\title{
Acetylene in breath: background levels and real-time elimination kinetics after smoking
}

\section{Metsälä, M \\ IOP Publishing \\ 2010}

Metsälä , M , Schmidt , F , Skyttä , M , Vaittinen , O \& Halonen , L 2010 , ' Acetylene in breath: background levels and real-time elimination kinetics after smoking ', Journal of Breath Research, vol 4 , no. 4 , pp. 046003.

http://hdl.handle.net/10138/23984

http://dx.doi.org/10.1088/1752-7155/4/4/046003

Downloaded from Helda, University of Helsinki institutional repository.

This is an electronic reprint of the original article.

This reprint may differ from the original in pagination and typographic detail.

Please cite the original version. 
Acetylene in breath: background levels and real-time elimination kinetics after smoking

This article has been downloaded from IOPscience. Please scroll down to see the full text article.

2010 J. Breath Res. 4046003

(http://iopscience.iop.org/1752-7163/4/4/046003)

View the table of contents for this issue, or go to the journal homepage for more

Download details:

IP Address: 128.214.16.192

The article was downloaded on 01/12/2010 at 08:39

Please note that terms and conditions apply. 


\title{
Acetylene in breath: background levels and real-time elimination kinetics after smoking
}

\author{
M Metsälä, F M Schmidt, M Skyttä, O Vaittinen and L Halonen \\ Laboratory of Physical Chemistry, Department of Chemistry, PO Box 55 (A.I. Virtasen aukio 1), \\ FIN-00014 University of Helsinki, Finland \\ E-mail: lauri.halonen@helsinki.fi
}

Received 31 August 2010

Accepted for publication 20 October 2010

Published 15 November 2010

Online at stacks.iop.org/JBR/4/046003

\begin{abstract}
We have measured the acetylene concentration in the exhaled breath of 40 volunteers ( 31 non-smokers, nine smokers) using near-infrared cavity ring-down spectroscopy. The acetylene levels were found to be the same as in ambient air for non-smokers, whereas elevated levels were observed for smokers. Real-time measurements with sub-second time resolution have been applied to measure the elimination kinetics of acetylene in breath after exposure to tobacco smoke. Three exponential time constants can be distinguished from the data and these can be used to define the residence times for different compartments, according to the multi-compartment model of the human body.
\end{abstract}

(Some figures in this article are in colour only in the electronic version)

\section{Introduction}

Acetylene $\left(\mathrm{C}_{2} \mathrm{H}_{2}\right)$ is a common hydrocarbon in the troposphere originating almost exclusively from anthropogenic sources [1]. The main sources of acetylene in the atmosphere are different combustion processes: vehicle exhausts and biomass burning. The outdoor acetylene concentration in an urban environment is normally about 1 part per billion by volume (ppbv). In a recent study, we measured indoor and outdoor acetylene concentrations in Helsinki, Finland and found highly fluctuating daytime outdoor acetylene levels [2]. The mean mixing ratio was 2 ppbv or below for both indoor and outdoor settings. In atmospheric studies, acetylene is often used as a marker for anthropogenic emissions and to trace polluted air masses. The acetylene concentration in the atmosphere correlates well with the concentrations of other volatile organic compounds (VOCs) [3] and that of carbon monoxide [4].

Acetylene has previously been detected in exhaled breath [5], but the concentration has not been quantified, to the best of our knowledge (except for one breath sample recorded by us [2]). Unless the human body acts as a sink for acetylene, one would expect to find levels that are at least as high as the concentration in ambient air. Short periods of exposure to high levels of combustion products might give rise to an elevated acetylene concentration in the body. As one cigarette has been found to release about $150 \mu \mathrm{g}$ of acetylene to the environment [6], it seems reasonable to assume that smokers exhibit higher concentrations of $\mathrm{C}_{2} \mathrm{H}_{2}$ in breath than non-smokers. Some bacteria have also been shown to produce small hydrocarbons like acetylene [7], and thus it is also possible that $\mathrm{C}_{2} \mathrm{H}_{2}$ is endogenously produced in the human body.

Different molecules have been suggested as biomarkers for the smoking status of an individual, using different matrices including urine, blood, hair, saliva and exhaled breath [8]. The most widely used biomarker in breath is carbon monoxide $[8,9]$ but other compounds, such as acetonitrile [10, 11], benzene, 1,3-butadiene and 2,5-dimethylfuran [12,13] have also been suggested. Of these molecules, 2,5-dimethylfuran seems to be most effective since it can be observed in breath more than $24 \mathrm{~h}$ after smoking and can even be used to detect heavy passive smokers and occasional social smokers [13].

Real-time trace gas analysis can be used to monitor the uptake and elimination kinetics of various compounds in breath [14-16]. This enables the execution of realtime pharmacokinetic studies, which aim to establish the processes and pathways of foreign chemical species in the 



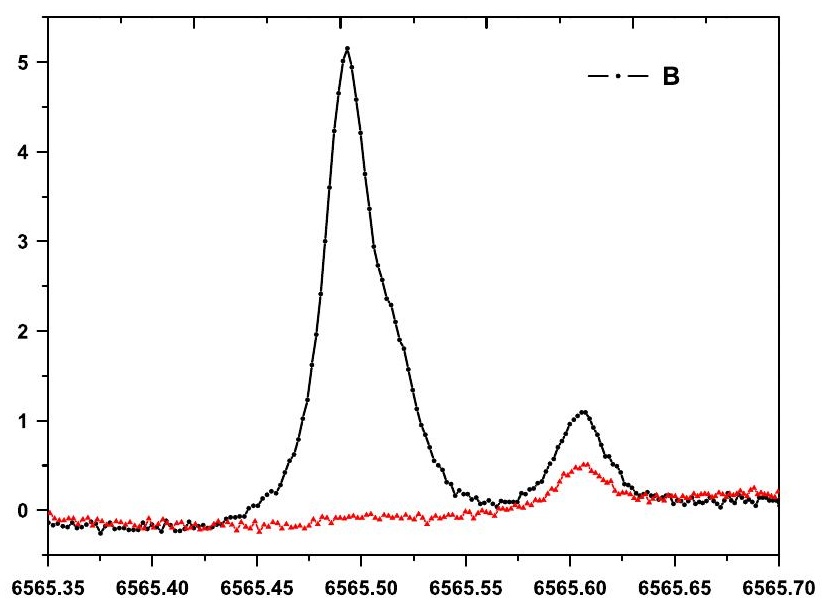




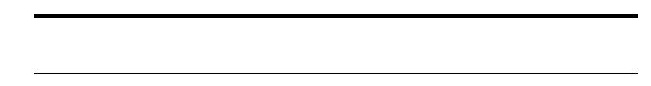




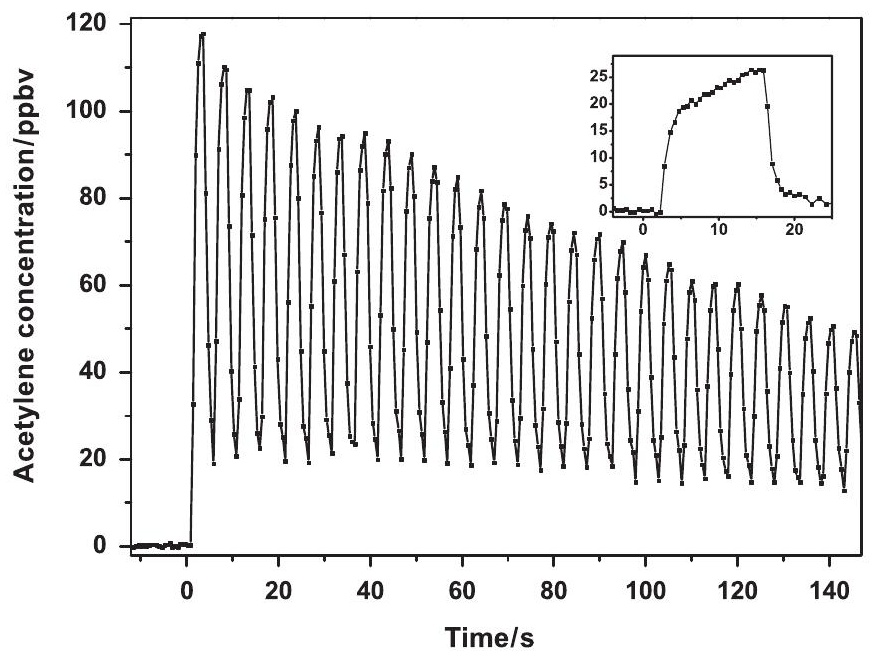

Figure 2. Real-time measurement of acetylene concentration in exhaled breath after cigarette smoking. Paced respiration rate of 12 breaths $\min ^{-1}$ was used. The inset shows a longer exhalation, where the alveolar slope is visible. The units in the inset are the same as in the main graph for both axes.

numbers and both media support acetylene production equally strong, we should have observed $\mathrm{C}_{2} \mathrm{H}_{2}$ concentrations of tens of ppbv. Thus, we are unable to reproduce the result obtained in [7], although the difference in the growth media should be emphasized.

\subsection{Elimination kinetics after exposure to tobacco smoke}

Figure 2 shows a sample of a real-time measurement of the acetylene mixing ratio in exhaled breath after cigarette smoking. The time resolution of the experiment was high enough to reveal the evolution of a single breath cycle at a paced respiration rate of 12 breaths $\min ^{-1}$. The inset in figure 2 shows a longer exhalation, where the alveolar slope is clearly visible. During the inhalation, the $\mathrm{C}_{2} \mathrm{H}_{2}$ concentration does not go to zero; this is due to the size of the buffer tube volume compared to the gas flow rate through the spectrometer. The acetylene-rich air in the buffer tube is not completely exchanged during the inhalation cycle because the inhaled air comes from the other side of the non-rebreathing valve.

The acetylene elimination in breath was followed for $1 \mathrm{~h}$ after smoking one cigarette. Paced breathing at 12 exhalations per minute was used. A representative decay graph is presented in figure 3 , where each individual point corresponds to a maximum of an exhalation cycle as explained in section 2.4. Altogether five $1 \mathrm{~h}$ measurements were made for subject no 1 and one measurement each for subjects no $2-5$. The decay parameters for subject no 1 are given in table 2 and for subjects no $2-5$ in table 3 . The data were fitted with two exponential decay functions according to equation 1 . The longer time constant likely represents tissues and the shorter one blood [21]. A systematic trend was noticed, where the first few points of every measurement cycle (when subject starts to breathe into the mouthpiece) correspond to lower acetylene concentrations than the following ones. For this reason, the first three points of every measurement cycle

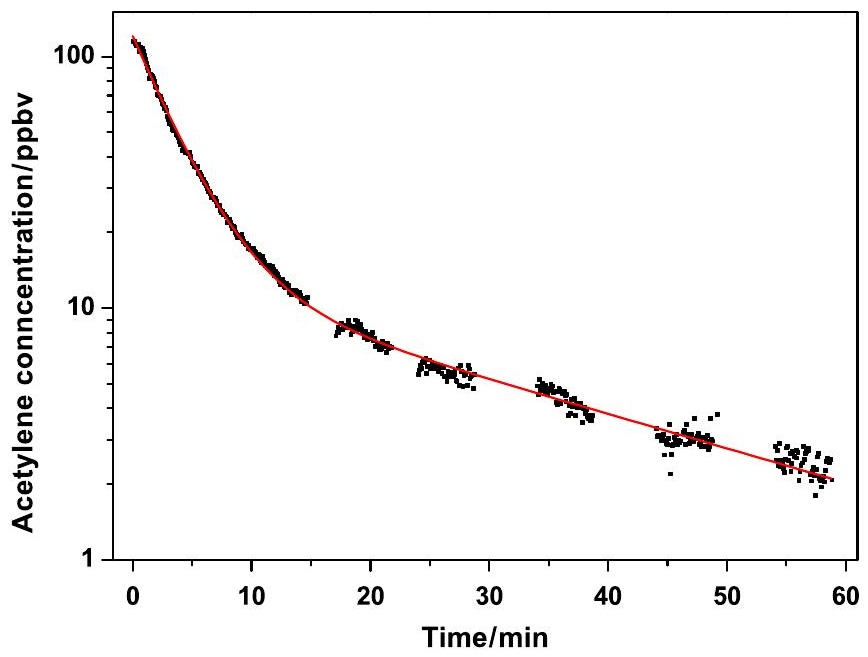

Figure 3. One hour measurement of acetylene elimination kinetics after smoking, semi-logarithmic plot. Black full circles are the experimental data points (subject no 1, measurement no 1) and the red line corresponds to a nonlinear least squares fit with two exponential decay functions.

Table 2. Acetylene decay parameters after cigarette smoking, subject no $1,1 \mathrm{~h}$ measurements at 12 exhalations $\min ^{-1}$. Parameters $A_{i}$ and $\tau_{i}$ refer to equation 1 . Uncertainties for parameters are standard errors of the nonlinear least squares fit. Stdev is standard deviation.

\begin{tabular}{lclll}
\hline Measurement & $A_{2}, \mathrm{ppbv}$ & $\tau_{2}, \mathrm{~s}$ & $A_{3}, \mathrm{ppbv}$ & $\tau_{3}, \mathrm{~s}$ \\
\hline 1 & $107.0 \pm 2.7$ & $217.9 \pm 8.3$ & $13.5 \pm 1.1$ & $1890 \pm 148$ \\
2 & $117.1 \pm 3.0$ & $192.5 \pm 7.0$ & $14.6 \pm 1.1$ & $1731 \pm 116$ \\
3 & $68.7 \pm 2.7$ & $163.2 \pm 9.4$ & $15.5 \pm 1.0$ & $1454 \pm 82$ \\
4 & $90.2 \pm 2.9$ & $157.4 \pm 6.9$ & $12.2 \pm 0.9$ & $1517 \pm 99$ \\
5 & $76.4 \pm 2.6$ & $183.0 \pm 8.6$ & $11.5 \pm 0.9$ & $1914 \pm 146$ \\
Mean & 91.9 & 182.8 & 13.5 & 1701 \\
Stdev & 20.3 & 24.3 & 1.7 & 210 \\
\hline
\end{tabular}

Table 3. Acetylene decay parameters after cigarette smoking, subjects no $2-5,1 \mathrm{~h}$ measurements at 12 exhalations $\mathrm{min}^{-1}$. Parameters $A_{i}$ and $\tau_{i}$ refer to equation 1. Uncertainties for parameters are standard errors of the nonlinear least squares fit. Stdev is standard deviation.

\begin{tabular}{lrlll}
\hline Subject & \multicolumn{1}{c}{$A_{2}, \mathrm{ppbv}$} & $\tau_{2}, \mathrm{~s}$ & $A_{3}, \mathrm{ppbv}$ & $\tau_{3}, \mathrm{~s}$ \\
\hline 2 & $261.8 \pm 5.0$ & $151.3 \pm 3.9$ & $37.3 \pm 1.5$ & $1418 \pm 49$ \\
3 & $151.5 \pm 4.0$ & $179.0 \pm 7.2$ & $40.9 \pm 1.6$ & $1650 \pm 58$ \\
4 & $91.0 \pm 3.6$ & $118.0 \pm 6.2$ & $19.7 \pm 0.9$ & $1452 \pm 59$ \\
5 & $199.5 \pm 4.5$ & $157.6 \pm 5.1$ & $34.3 \pm 1.7$ & $1237 \pm 45$ \\
Mean & 176.0 & 151.5 & 33.1 & 1439 \\
Stdev & 72.4 & 25.3 & 9.3 & 169 \\
\hline
\end{tabular}

were deleted from the dataset. This artifact is probably due to the subjects adjusting themselves to breathing through the mouthpiece. It is known that the use of a mouthpiece and a nose clip influences the breathing pattern and increases the tidal volume [27].

To measure the fast washout process from the lungs, we also made $5 \mathrm{~min}$ short measurements of the acetylene elimination process with a higher ventilation rate, 20 exhalations per minute. In these measurements, a third 
Table 4. Acetylene decay parameters after cigarette smoking, subject no 1,5 min measurements at 20 exhalations $\min ^{-1}$. Parameters $A_{i}$ and $\tau_{i}$ refer to equation 1 . The longest time constant $\left(\tau_{3}\right)$ is fixed to $1600 \mathrm{~s}$ in the fitting procedure. Uncertainties for parameters are standard errors of the nonlinear least squares fit. Stdev is standard deviation.

\begin{tabular}{lrlclcl}
\hline Measurement & $A_{1}, \mathrm{ppbv}$ & \multicolumn{1}{c}{$\tau_{1}, \mathrm{~s}$} & \multicolumn{1}{c}{$A_{2}, \mathrm{ppbv}$} & \multicolumn{1}{c}{$\tau_{2}, \mathrm{~s}$} & $A_{3}, \mathrm{ppbv}$ & $\tau_{3}$ (fixed), \\
\hline 1 & $32.0 \pm 1.7$ & $2.1 \pm 0.3$ & $113.2 \pm 0.8$ & $119.3 \pm 2.7$ & $26.5 \pm 1.0$ & 1600 \\
2 & $25.3 \pm 1.7$ & $3.9 \pm 0.6$ & $127.0 \pm 0.9$ & $121.8 \pm 2.8$ & $27.5 \pm 1.1$ & 1600 \\
3 & $7.1 \pm 1.6$ & $3.0 \pm 1.7$ & $94.1 \pm 1.5$ & $162.8 \pm 6.5$ & $18.1 \pm 1.9$ & 1600 \\
4 & $50.8 \pm 2.5$ & $7.0 \pm 0.7$ & $116.4 \pm 3.6$ & $186.9 \pm 13.3$ & $9.4 \pm 4.7$ & 1600 \\
Mean & 28.8 & 4.0 & 112.70 & 147.7 & 20.4 & \\
Stdev & 18.0 & 2.1 & 13.7 & 32.9 & 8.4 & \\
\hline
\end{tabular}

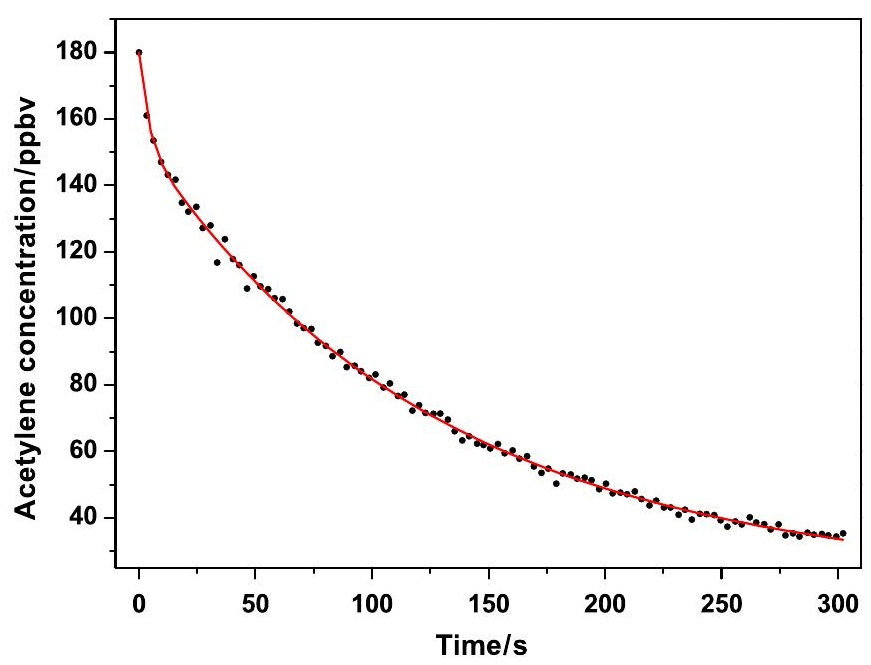

Figure 4. Five minute measurement of acetylene elimination kinetics after smoking. Black full circles are the experimental points (subject no 1, measurement no 2) and the red line corresponds to a nonlinear least squares fit with three exponential decay functions.

exponential component with a time constant in the order of few seconds was visible. Altogether four of these measurements were made with subject no 1 , the decay parameters are summarized in table 4. A representative graph is presented in figure 4. No points were discarded in the analysis of these measurements. Three exponentials were fitted to these data; the time constant of the slowest one was fixed to $1600 \mathrm{~s}$ but the amplitude was left to vary.

\section{Discussion and conclusions}

The $\mathrm{C}_{2} \mathrm{H}_{2}$ concentration measurements made using sample bags demonstrate that the acetylene mixing ratios in the breath of non-smokers are the same as in ambient air. Smokers exhibit higher mixing ratios in their breath compared to ambient air and this makes it possible to distinguish active smokers from non-smokers. Within the admittedly limited population of our study the sensitivity and specificity for the detection of smokers were $100 \%$. However, based on the elimination kinetics measurements, acetylene cannot be used to detect smokers for a very long time after the last cigarette. After 2 to $3 \mathrm{~h}$, the acetylene level will return to that of ambient air. In that respect, acetylene cannot compete as a biomarker for smoking status with molecules like 2,5-dimethylfuran, which can be detected at elevated levels more than $24 \mathrm{~h}$ after the last cigarette [13]. An additional complication arises because acetylene is not a truly specific marker for tobacco smoke since exposure to other types of combustion products will also result in an elevated acetylene level. The advantage of acetylene is that it does not seem to be produced endogenously in healthy subjects and thus the baseline level in breath is very low. This is in contrast to, for example, carbon monoxide, which is present at parts-per-million by volume (ppmv) levels even in the breath of non-smokers [9].

The elimination kinetics measurements after smoking demonstrate the power of highly sensitive real-time laser spectroscopy. We can even distinguish the rapid wash-out process from the lungs that happens on the time scale of seconds. In the case of exposure to tobacco, this washout is of limited meaningfulness. Looking at the results in table 4, especially measurement no 3 , it is clear that there is a large intra-individual variation in the amplitude and time constant of this fastest decay process. This is most likely due to differences in how the cigarette is smoked and how deep the last puff is. If the exposure was done in a more controlled way, the washout phenomenon from the lungs would most likely be more repeatable. However, the number of data points (even at 20 breaths $\mathrm{min}^{-1}$ ) is small for the time scale of the fast decay, resulting in a fairly inaccurate determination of this parameter. For the longer time constants, the inter- and intra-individual variation is smaller. Amplitudes of the decay are clearly dependent on the smoking style but the values of the time constants are quite reproducible. Furthermore, as is seen in table 2, for the same subject, even the amplitudes are reproducible from measurement to measurement. Comparing the $5 \mathrm{~min}$ and $1 \mathrm{~h}$ measurements for subject no 1 it seems that a faster respiration rate $\left(20\right.$ breaths $\mathrm{min}^{-1}$ versus 12 breaths $\mathrm{min}^{-1}$ ) results in a shorter time constant for the second compartment.

Breathing through the mouthpiece for extended times is not trivial and some people find it more difficult than others. Variations in breathing technique during the measurement are reflected in the retrieved instantaneous acetylene levels and cause irregularities in the decay curve. Thus, the quality of the elimination data varies significantly from subject to subject. Reassuringly, however, the fitted decay parameters are reproducible and do not seem to be affected by minor artifacts in the data.

The total averages over all measurements (12 breaths $\min ^{-1}$ ) for the second and third time constants (tables 2 and 3) are $169 \mathrm{~s}$ and $1585 \mathrm{~s}$, respectively. These values compare 
reasonably well with observations for other VOCs. Von Basum et al [14] measured mean values (three subjects) of $49 \mathrm{~s}$ and $1110 \mathrm{~s}$ for the second and third compartments, respectively, after exposure to ethane. They also report the mean value for the first compartment (washout from lungs) as $18 \mathrm{~s}$ but due to the low respiration rate used in that study (4 breaths $\min ^{-1}$ ) they had only a few data points on the time scale of the first decay process. For the elimination of benzene, 1,3butadiene and 2,5-dimethylfuran after smoking, Gordon et al [12] used a two-compartment model and retrieved mean values (five subjects) between $30-50 \mathrm{~s}$ for the second compartment for the different compounds and about $840 \mathrm{~s}$ for the third. For trichloroethene, mean values (six subjects) of $210 \mathrm{~s}$ and $3780 \mathrm{~s}$ were measured for the second and third compartments, respectively [28].

It is quite clear that the largest errors in our measurements are not connected with the laser spectroscopic analysis. The bottleneck is rather the sampling of the breath. In order to control and standardize the sampling event, simultaneous recording of the tidal volume and $\mathrm{CO}_{2}$ concentration could be used to characterize the end-tidal part of the exhalation cycle [29]. The bag samples collected in this study were full breath samples and were thus diluted with the dead-space contribution from the mouth and airways. For non-smokers, we could not find any difference in acetylene mixing ratio between the beginning of the exhalation cycle and the end-tidal part. For smokers, we can see a clear alveolar slope (visible in figure 2) and the bag measurements thus represent a mixture of the dead-space and end-tidal acetylene mixing ratios. The most important improvement could be obtained for the elimination kinetics measurements. The short-term irregularities observed in the decay curves would most likely be accounted for if the data were normalized in real-time to tidal volume and/or $\mathrm{CO}_{2}$ concentration.

\section{Acknowledgments}

The authors are grateful to the Academy of Finland for financial support. We would also like to thank Ms Raili Lameranta (Department of Biosciences, University of Helsinki) for growing the Proteus mirabilis cultures.

\section{References}

[1] Kanakidou M, Bonsang B, Le Roulley J C, Lambert G, Martin D and Sennequier G 1998 Marine source of atmospheric acetylene Nature 333 51-2

[2] Schmidt F M, Vaittinen O, Metsälä M, Kraus P and Halonen L 2010 Direct detection of acetylene in air by continuous wave cavity ring-down spectroscopy Appl. Phys. B in press, doi:10.1007/s00340-010-4027-5

[3] Liu Y, Shao M, Lu S, Chang C, Wang J L and Chen G 2008 Volatile organic compound (VOC) measurements in the Pearl river delta (PRD) region, China Atmos. Chem. Phys. 8 1531-45

[4] Xiao Y, Jacob D J and Turquety S 2007 Atmospheric acetylene an its relationship with $\mathrm{CO}$ as an indicator of air mass age J. Geophys. Res. 112 doi:10.1029/2006JD008268

[5] Röper J and Kochen W 1989 Detection of volatile hydrocarbons in human breath by megapore capillary gas-chromatography in the low ppb range Fresenius $Z$. Anal. Chem. 333747

[6] Persson K A, Berg S, Törnqvist M, Scalia-Tomba G P and Ehrenberg L 1988 Note on ethene and other low-molecular weight hydrocarbons in environmental tobacco smoke Acta Chem. Scand. B 42 690-6

[7] Fukuda H, Fuji T and Ogawa T 1984 Microbial production of C2-hydrocarbons, ethane, ethylene and acetylene Agric. Biol. Chem. 48 1363-5

[8] Shields P G 2002 Tobacco smoking, harm reduction, and biomarkers J. Natl. Cancer Inst. 94 1435-44

[9] Middleton E T and Morice A H 2000 Breath carbon monoxide as an indication of smoking habit Chest 117 758-63

[10] Jordan A, Handel A, Holzinger R and Lindinger W 1995 Acetonitrile and benzene in the breath of smokers and non-smokers investigated by proton transfer reaction mass spectrometry (PTR-MS) Int. J. Mass Spectrom. Ion Process 148 L $1-3$

[11] Lirk P, Bodrogi F, Deibl M, Kähler C M, Colvin J, Moser B, Pinggera G, Raifer H, Rieder J and Schobersberger W 2004 Quantification of recent smoking behaviour using proton transfer reaction-mass spectrometry (PTR-MS) Wien. Klin. Wochenschr. 116 21-5

[12] Gordon S M, Wallace L A, Brinkman M C, Callahan P J and Kenny D V 2002 Volatile organic compounds as breath biomarkers for active and passive smoking Environ. Health Perspect. 110 689-98

[13] Alonso M, Castellanos M and Sanchez J M 2010 Evaluation of potential breath biomarkers for active smoking: assessment of smoking habits Anal. Bioanal. Chem. 396 2987-95

[14] von Basum G, Dahnke H, Halmer D, Hering P and Mürtz M 2003 Online recording of ethane traces in human breath via infrared laser spectroscopy J. Appl. Physiol. 95 2583-90

[15] Halmer D, Thelen S, Hering P and Mürtz M 2006 Online monitoring of ethane traces in exhaled breath with a difference frequency generation spectrometer Appl. Phys. B 85 437-43

[16] Berkelmans H W A, Moeskops B W M, Bominaar J, Scheepers P and Harren F J M 2003 Pharmacokinetics of ethylene in man by on-line laser photoacoustic detection Toxicol. Appl. Pharmacol. $190206-13$

[17] Blake R S, Monks P S and Ellis A M 2009 Proton-transfer reaction mass spectrometry Chem. Rev. 109 861-96

[18] Smith D and Španěl P 2004 Selected ion flow tube mass spectrometry (SIFT-MS) for on-line trace gas analysis Mass. Spectrom. Rev. 24 661-700

[19] Berden G and Engeln R (eds) 2009 Cavity Ring-Down Spectroscopy: Techniques and Applications (Wiltshire: Blackwell)

[20] McCurdy M R, Bakhirkin Y, Wysocki G, Lewicki R and Tittel F K 2007 Recent advances of laser-spectroscopy-based techniques for applications in breath analysis J. Breath Res. 1014001

[21] Wallace L, Pellizzari E and Gordon S 1993 A linear model relating breath concentrations to environmental exposures: application to a chamber study of four volunteers exposed to volatile organic chemicals J. Expo. Anal. Environ. Epidemiol. 3 75-102

[22] Romanini D, Kachanov A A, Sadeghi N and Stoeckel F 1997 CW cavity ring down spectroscopy Chem. Phys. Lett. 264 316-22

[23] Roemer E, Stabberta R, Rustemeiera K, Veltela D J, Meisgena T J, Reininghausa W, Carchmanb R A, Gaworskic C L and Podrazac K F 2004 Chemical composition, cytotoxicity and mutagenicity of smoke from US commercial and reference cigarettes smoked under two sets of machine smoking conditions Toxicology $19531-52$ 
[24] El Hachtouki R and Vander Auwera J 2002 Absolute line intensities in acetylene: the $1.5-\mu \mathrm{m}$ region $\mathrm{J}$. Mol. Spectrosc. 216 355-62

[25] The FITYK software (www.unipress.waw.pl/fityk)

[26] Stamyr K, Vaittinen O, Jaakola J, Guss J, Metsälä M, Johanson G and Halonen L 2009 Background levels of hydrogen cyanide in human breath measured by infrared cavity ring down spectroscopy Biomarkers 14 285-91
[27] Askanazi J, Silverberg P A, Foster R J, Hyman A I, Milic-Emili J and Kinney J M 1980 Effects of respiratory apparatus on breathing pattern J. Appl. Physiol. 48 577-80

[28] Pleil J D, Fisher J W and Lindstrom A B 1998 Trichloroethene levels in human blood and exhaled breath from controlled inhalation exposure Environ. Health Perspect. 106 531-3

[29] Cope K A, Watson M T, Foster W M, Sehnert S S and Risby T H 2004 Effects of ventilation on the collection of exhaled breath in humans J. Appl. Physiol. 96 1371-9 